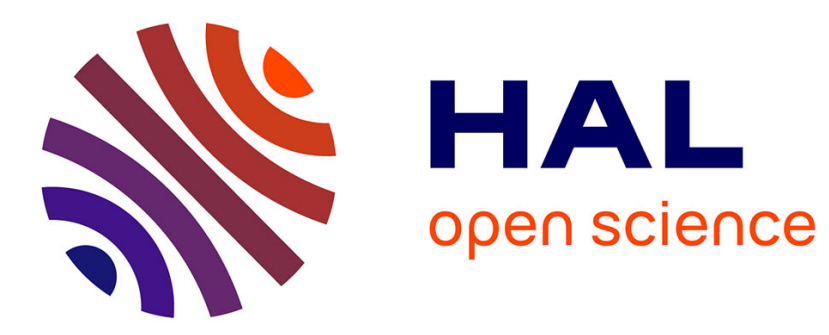

\title{
Some aspects of cross-slip mechanisms in metals and alloys
}

\author{
Daniel Caillard, J.L. Martin
}

\section{To cite this version:}

Daniel Caillard, J.L. Martin. Some aspects of cross-slip mechanisms in metals and alloys. Journal de Physique, 1989, 50 (18), pp.2455-2473. 10.1051/jphys:0198900500180245500 . jpa-00211074

\section{HAL Id: jpa-00211074 https://hal.science/jpa-00211074}

Submitted on 1 Jan 1989

HAL is a multi-disciplinary open access archive for the deposit and dissemination of scientific research documents, whether they are published or not. The documents may come from teaching and research institutions in France or abroad, or from public or private research centers.
L'archive ouverte pluridisciplinaire HAL, est destinée au dépôt et à la diffusion de documents scientifiques de niveau recherche, publiés ou non, émanant des établissements d'enseignement et de recherche français ou étrangers, des laboratoires publics ou privés. 
Classification

Physics Abstracts

$62.20 \mathrm{H}$

\title{
Some aspects of cross-slip mechanisms in metals and alloys
}

\author{
D. Caillard $\left(^{1}\right)$ and J. L. Martin $\left(^{(2)}\right.$ \\ (') Laboratoire d'Optique Electronique du CNRS, B.P. 4347, F-31055 Toulouse Cedex, France \\ (2) Institut de Génie Atomique, Ecole Polytechnique Fédérale de Lausanne, CH-1015 Lausanne, \\ Switzerland
}

(Reçu le 6 mars 1989, accepté sous forme définitive le 24 mai 1989)

\begin{abstract}
Résumé. - Des modèles ont été proposés pour décrire le glissement dévié des dislocations dans les métaux de structure CFC et HC. On montre comment ces modèles se sont développés et comment des résultats expérimentaux récents confirment leurs prédictions. Quelques aspects macroscopiques de la plasticité des cristaux tels que les énergies d'activation de fluage, les anomalies de limite élastique et les stades de durcissement sont discutés à la lumière de ces modèles microscopiques.
\end{abstract}

\begin{abstract}
Dislocation cross slip in FCC and HCP metals has been described in terms of various models. The development of these models is reviewed and their predictions are compared with recent experimental observations. Some macroscopic features of plastic deformation (creep activation energies, strength anomalies and deformation stages) are examined in the light of these microscopic mechanisms.
\end{abstract}

\section{Introduction.}

Cross slip occurs when the local stresses push a dislocation into a plane which is different from the original plane of splitting. It has been evidenced long ago by the observation of slip traces at sample surfaces. The outlines of the first realistic models were then derived by Friedel, both for face-centered cubic (FCC) metals [1] in 1956 on the basis of calculations of Stroh (1954) [2] and for hexagonal close-packed (HCP) metals [3] in 1959. In the mean time, another theory for dislocation cross slip was developed (see e.g. Refs. [4] and [5]).

Later on, similar slip trace observations, after creep at intermediate temperatures, led some authors to interpret the corresponding activation energies in terms of cross-slip (Lytton et al., 1958 [6] ; Friedel, 1959 [3] and 1964 [7]). This mechanism has also been claimed to be the key process at the transition stress $\tau_{\text {III }}$ between the hardening stages II and III of FCC metals (Schoeck and Seeger, 1955 [4] ; Friedel, 1956 [1] and Haasen, 1967 [8]).

More recently, the importance of cross slip in the plasticity of metals has however been ignored or underestimated.

In the present paper, we attempt to describe how these first ideas developed with time into detailed models, and how these have been confirmed or improved recently through 
sophisticated deformation tests, or electron microscope observations. The latter consist mainly of in situ deformation experiments, which have been recently described as a new technique to investigate old problems [9]. We first review the results related to cross slip in FCC metals and then consider Peierls type friction related to slip in body centred cubic (BCC) metals and non compact slip in metals with a close packed structure. We then summarize the results concerning a newly observed type of friction, the «locking-unlocking mechanism », both for prismatic slip of beryllium and slip in $L_{12}$ ordered structures. Macroscopic aspects of plastic deformation such as strength anomalies, creep activation energies, deformation stages of the FCC metals are then discussed in terms of the above dislocation mechanisms.

\section{Cross slip in FCC metals.}

The elementary process of dislocation cross slip from a compact plane onto another compact plane although frequently observed experimentally, is a very poorly known process.

The theoretical aspects of cross slip have been studied by Escaig $(1968[10,11])$, following Friedel's view. In his model, cross slip occurs through the mechanism sketched in figure 1 . It starts from a primary constriction on a screw dislocation. Under the influence of the applied stress aided by thermal activation, the two halves of the constriction are separated and, as suggested by Friedel (1956 [1], 1957 [12]), the dislocation segment between them, splits at once on the cross slip plane. This model seems to be more realistic than the former one of Schoeck and Seeger (1955) [4]. In particular, Escaig has shown that the process depends mainly on the ratio of the width of splitting under stress on the primary and the cross slip planes. This causes the process to be orientation dependent, which will be discussed below.

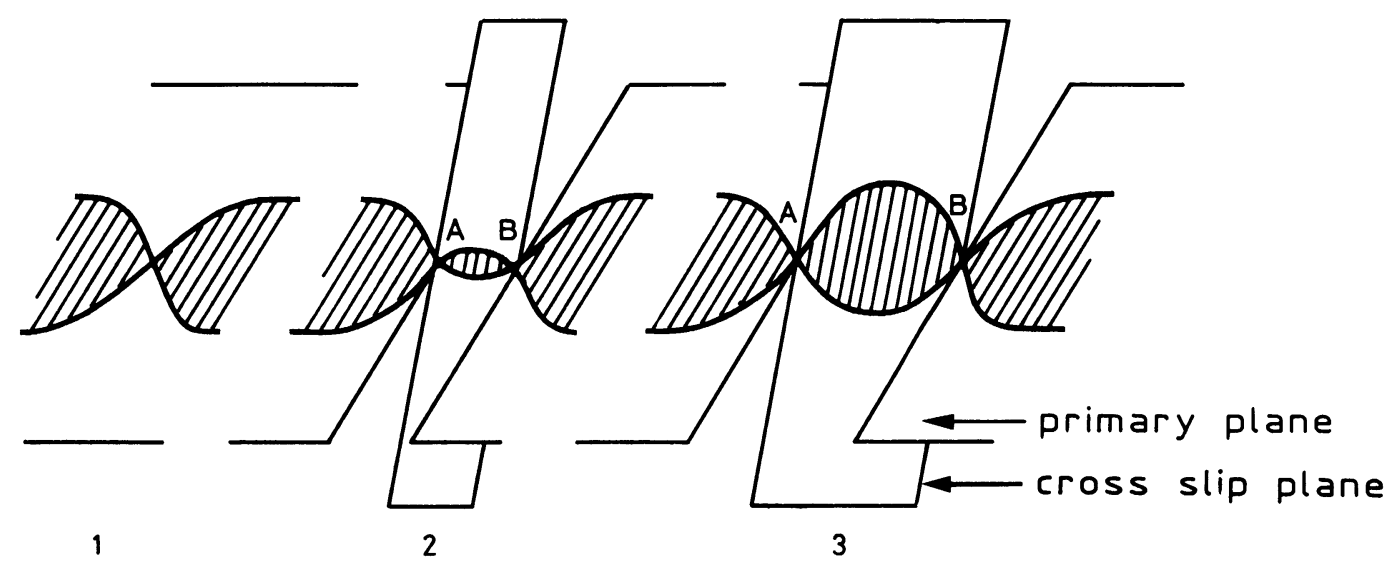

Fig. 1. - Successive stages of cross-slip starting at a constriction, in Friedel's and Escaig's model [1, 10, 11].

The activation energy $\Delta G_{\mathrm{CS}}$ has been derived for weak effective stresses :

$$
\Delta G_{\mathrm{CS}}(i)=2 i A D_{0}^{2} f\left[\left(1-b_{0} / D_{0}\right)^{2}-\alpha(i) \tau b / f\right]
$$

with $i=1$ or 2 depending on how many constrictions are necessary to initiate the process ; $b_{0}$ is the width of a recombined screw dislocation ; $\mu$ the shear modulus, $\alpha(i)$ an orientation dependent parameter ; $\tau$ is the applied resolved shear stress ; $f$ the stacking fault energy ; 
$D_{0}$ the dissociation width at zero stress; $A$ is a slowly variable function of $\mu, b$, $f$. The activation volume of the process is :

$$
V_{\mathrm{CS}}=2 i \alpha(i) A D_{0}^{2} b \text {. }
$$

A new experimental technique has been developed to produce a burst of cross slip at the yield point [13] : a copper single crystal is deformed in compression along [110] to the end of stage II to produce a homogeneous dislocation forest. New samples are then cut out of this crystal, in a single slip orientation. The new primary dislocations are expected to cross slip at the yield point because of the numerous forest dislocations acting as obstacles. The tension compression asymmetries predicted by the model, as well as the orientation dependence of the critical stress for cross slip, are in good agreement with experimental results obtained at room temperature. As the temperature is changed, load relaxation experiments are performed along the stress strain curves to obtain activation volumes. An example is shown in figure 2 for a predeformation experiment at $473 \mathrm{~K}$. The corrected activation volume exhibits a minimum as a function of strain. This corresponds to a value of about 300 atomic volumes, in fairly good agreement with equation (2) and the width of splitting of copper. The stress corresponding to this minimum is then considered to be the critical stress for cross slip, which is confirmed by slip trace observations. The variation as a function of temperature of this critical stress and of the corresponding activation volume, is shown in figure 3 [14]. The barrier energy for cross slip in copper was estimated to be : $\Delta G_{\mathrm{CS}}^{\circ}=1.15 \pm 0.37 \mathrm{eV}$, which falls between the two values predicted by equation (1) for $i=1$ and 2 respectively. An important conclusion is that after the above measurements, it became obvious that the $\tau_{\text {III }}$ stress and its variation as a function of temperature are different from the critical stress for cross slip between compact planes. The above experimental results, especially the orientation dependance of the critical stress for cross slip, are clearly in favor of Friedel's and Escaig's views. The comparison with the second type of theory for cross slip [4] and [5] has already been given elsewhere [13]. Similar orientation effects have also been found in $\mathrm{Ni}_{3} \mathrm{Al}$ and interpreted successfully using the Friedel-Escaig cross slip theory [15].

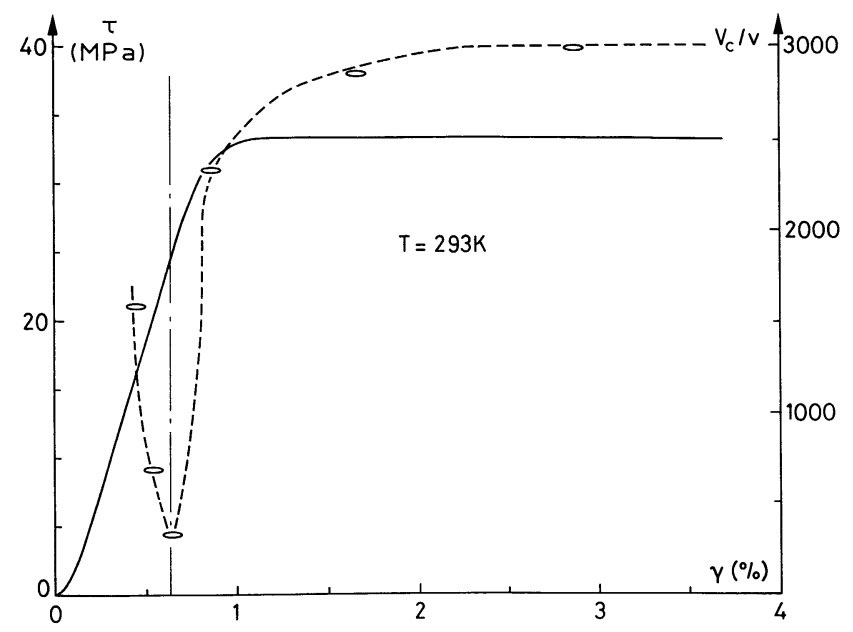

Fig. 2. - Resolved shear stress and corrected activation volume as a function of resolved shear strain. $\mathrm{Cu}$ single crystals. Deformation tests at $293 \mathrm{~K}$. Predeformation tests at $473 \mathrm{~K}$ [14]. 


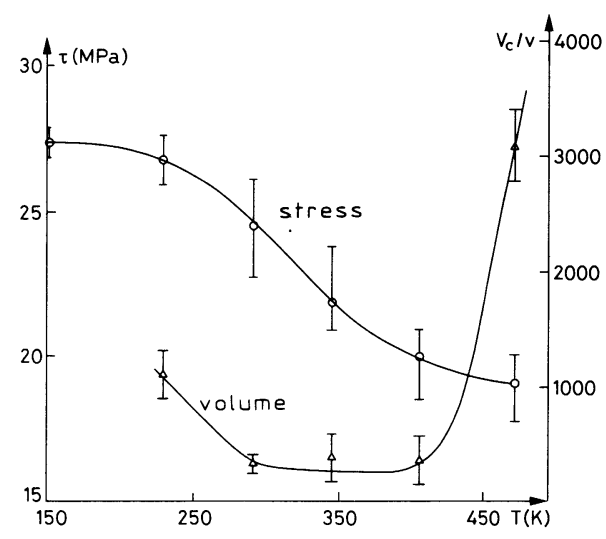

Fig. 3. - Critical stress for cross slip and corresponding activation volume as a function of temperature in $\mathrm{Cu}$. Cross slip takes place at the macro elastic limit $\tau$ between 250 and $410 \mathrm{~K}$. $v$ is the atomic volume [14].

\section{Friction forces of the Peierls type.}

The principle of this kind of friction force is that the energy of moving dislocations necessarily varies according to the lattice periodicity. Dislocations thus have their minimum energy in the so called «Peierls valleys", and their movement can be described as a series of jumps between adjacent valleys, through the nucleation and propagation of kink pairs.

In the early model of Peierls and Nabarro, the dislocations are assumed to spread only in their glide planes. This results in very low friction forces, especially for dislocations which are largely split (case of glide on the most compact planes).

More recent studies have shown that even larger frictional forces can originate when dislocations spread out of their glide plane. Under such conditions, the Peierls mechanism can play a very important role in the plasticity of materials, even at high temperatures. This is for instance the case of $L_{12}$ ordered alloys, for which friction forces are present up to $0.7 T_{\mathrm{m}}\left(T_{\mathrm{m}}\right.$ : melting temperature).

These higher friction forces are found to concern mainly screw dislocations, which can spread more easily in different planes, because of their higher symmetry within the crystal lattice. In order to move the dislocation, it is necessary to recombine its core, which involves the same fundamental mechanisms as for cross slip.

The first ideas about this mechanism were suggested by Hirsch (1960) [16] and Yoshinaga and Horiuchi (1963) [17] for BCC and HCP metals, respectively. Detailed models, based on the recombination of dislocations dissociated into several partials, have been derived by Kroupa (1963) [8], Schottky et al. (1965) [19], Vitek (1966) [20] and Escaig (1968) [21]. Recent calculations by Seeger (1984) [22] based on sophisticated kink-kink interactions, do not use any description of the recombination process of dislocations spread out of their glide plane (cross slip description).

The similitudes and differences between the early «classical» model of Peierls and Nabarro, and the model including the spreading of dislocations out of their glide plane (sometimes called "pseudo Peierls » or « kink pair mechanism ») have been discussed by Friedel (1968) [23]. The differences between this and the classical Peierls case only concern details :

- the core energy shows more acute minima, where the dislocation can split ; 
- the long range interaction between kinks depends on the way the kinks locally affect the splitting ;

- the active applied stresses are both in the slip plane and in the splitting planes (« Escaig effect »).

Experimental data on the Peierls mechanism are summarized below.

3.1 PEIERLS STRESSES IN BCC METALS. - The dislocation movement has been studied in situ in a high voltage electron microscope by Furubayashi (1969) [24] and Louchet, Kubin and Vesely (1979) [25]. The Peierls mechanism was clearly identified for the first time by the rectilinear shape and the slow and smooth movement of the screws.

3.2 Peierls STRESSES IN HCP METAls (PRISMATIC SLIP). - In the case of titanium, which glides more easily on the prismatic than the basal plane, the observations of Naka et al. (1988) [26] also reveal strong frictional forces on screw dislocations gliding in prismatic planes. This friction corresponds to a non planar spreading as in BCC metals.

The Peierls mechanism has also been clearly identified by in situ observations in magnesium, in which glide is easier on the basal than on the prismatic plane, above room temperature [27]. The tensile axis was chosen parallel to the basal plane, so that the latter was unstressed and prismatic glide only is activated. The dislocation behaviour, observed in a $200 \mathrm{kV}$ electron microscope corresponds to a smooth movement of rectilinear screw dislocations, unlike non screw portions, which glide much faster (see Fig. 4).
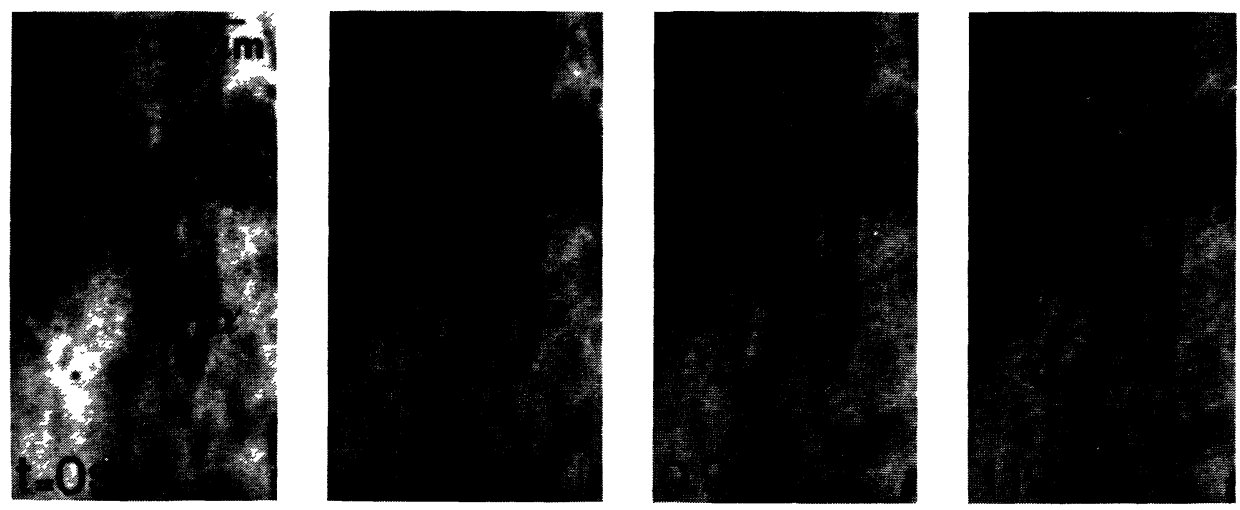

Fig. 4. - Dislocation glide in the prismatic plane of magnesium. Evidence of friction forces on screw dislocations $\alpha, \beta$ and $\gamma$. In situ experiment $120 \mathrm{kV}, 300 \mathrm{~K}$ [27].

The corresponding mechanism is detailed in figure 5. Screw dislocations are spread in the basal plane and glide in the prismatic plane by nucleating and propagating kink pairs.

More clearly than in BCC metals, it appears in magnesium that the generalized Peierls mechanism involves cross slip. In the configuration $5 \mathrm{c}$, screw dislocations are glissile in the basal plane. Large amplitude basal to and fro movements thus occur under internal stresses and add to prismatic movements (Fig. 6). This experiment clearly shows that screw dislocations really cross slip between basal and prismatic planes during the process.

Quantitative evaluations of the dislocation velocities as a function of stress and temperature yield an activation area of $9 b^{2}$ at room temperature and an activation energy at zero stress $\Delta G_{\mathrm{p}}^{\circ}$ close to $1.2 \mathrm{eV}$ (see the rate Eq. $\S 3.4$ below). 

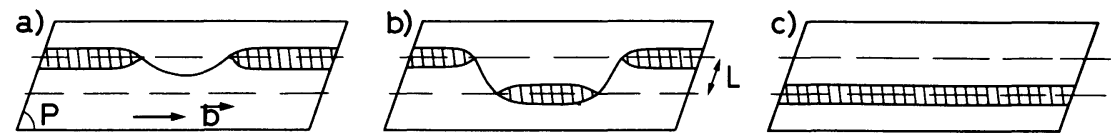

Fig. 5. - Schematic representation of a screw dislocation gliding on the prismatic plane $\mathbf{P}$ of an $\mathrm{HCP}$ crystal following the kink pair mechanism. $L=$ distance between compact rows $(L=c / 2)$. The hatched portions of the dislocation lie on the basal plane (perpendicular to $P$ ).

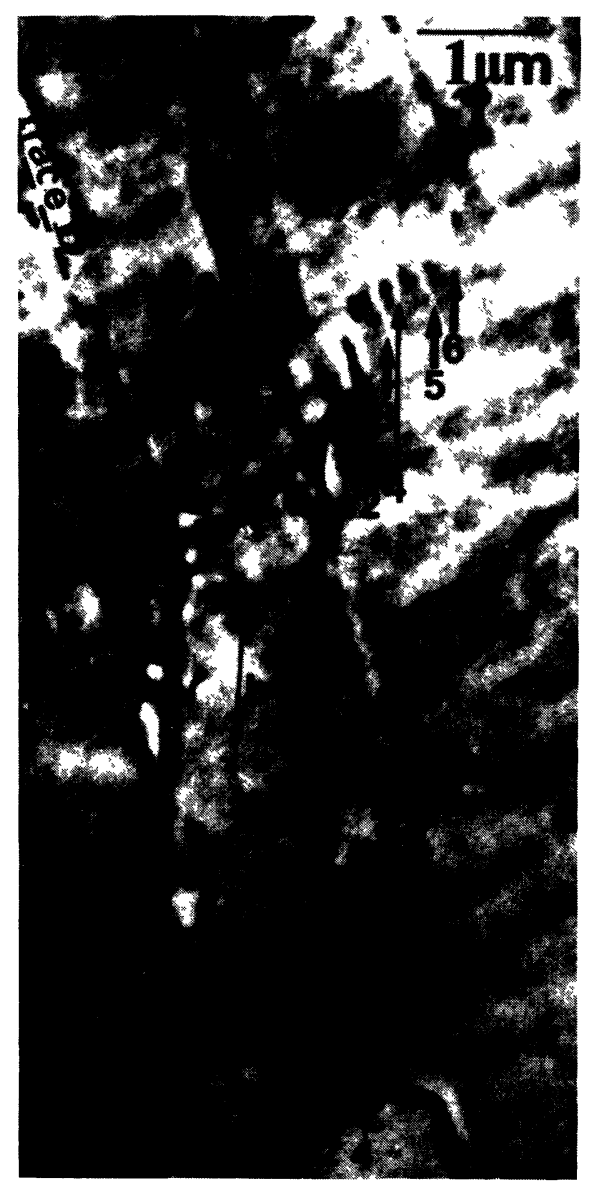

Fig. 6. - Wavy movement of a screw dislocation (S) in Mg (in situ TEM experiment $120 \mathrm{kV}$ ), $20^{\circ} \mathrm{C}$. Arrows underline oscillations of the two dislocation traces, parallel to the basal trace (B). (b : Burgers vector). From [27].

3.3 PEIERLS STRESSES IN FCC METALS (NON COMPACT SLIP). - Although these metals deform easily by glide on the octahedral planes, slip line observations long ago revealed that glide can also take place on non compact planes (see review by Carrard et al., 1987 [28]).

In aluminium above $200{ }^{\circ} \mathrm{C}$, for example, these non compact planes were of the $\{100\},\{110\},\{112\}$ and $\{113\}$ type. A detailed quantitative study of $\{110\}$ slip was undertaken in various FCC metals [29]. Slip trace replicas were observed by transmission 
electron microscopy (TEM) and showed that $\{110\}$ slip exists per se and is not the net result of composite slip on $\{111\}$. It was also shown, through constant strain rate tests, that $\{110\}$ slip is thermally activated. It starts operating above a critical temperature. For low stacking fault energy metals, this temperature is a higher fraction of the absolute melting point. This suggests that some kind of cross slip process is involved in the operation of non compact slip.

A detailed study of the mechanism related to (001) slip in 112 aluminium single crystals has been undertaken more recently [28] [30]. Although the high symmetry of the FCC crystals makes it impossible to neutralize the four $\{111\}$ planes at the same time, the [112] orientation allows extensive [110] (001) glide to be activated (see stereographic projection of Fig. 7 and Fig. 8).

Stress strain curves of different shapes are observed as a function of the active slip system (see Fig. 9). If compact slip only is operating, a monotonic increase of stress is observed as a function of strain, the curves exhibiting an approximately parabolic shape. If (001) slip operates, the curves start with a steep increase in stress and then exhibit a sharp decrease in hardening rate. It could be established that the latter corresponds to the critical stress $\tau_{001}$ at which (001) slip starts operating for a given temperature and strain rate. The stress $\tau_{001}$ was plotted as a function of temperature for different strain rates (Fig. 10). It can be seen that an athermal plateau is reached slightly above $400{ }^{\circ} \mathrm{C}$, that $\tau_{001}$ is strongly temperature dependent below $400{ }^{\circ} \mathrm{C}$ and that it cannot be measured below $270{ }^{\circ} \mathrm{C}$ where compact slip takes over. It was possible to measure an apparent activation enthalpy for (001) glide, $\Delta H_{001}=1.74 \mathrm{eV}$, from the curves of figure 10 .

These conclusions where confirmed by in situ experiments [28, 32] and by the observation of long straight screw dislocations pinned under load after creep of Al-Zn single crystals [31].

A microscopic mechanism of the Peierls type for (001) slip was proposed taking into account the above macroscopic and microstructural observations. It presents some similarities with the preceding mechanism in HCP metals, and can easily be extended to other types of

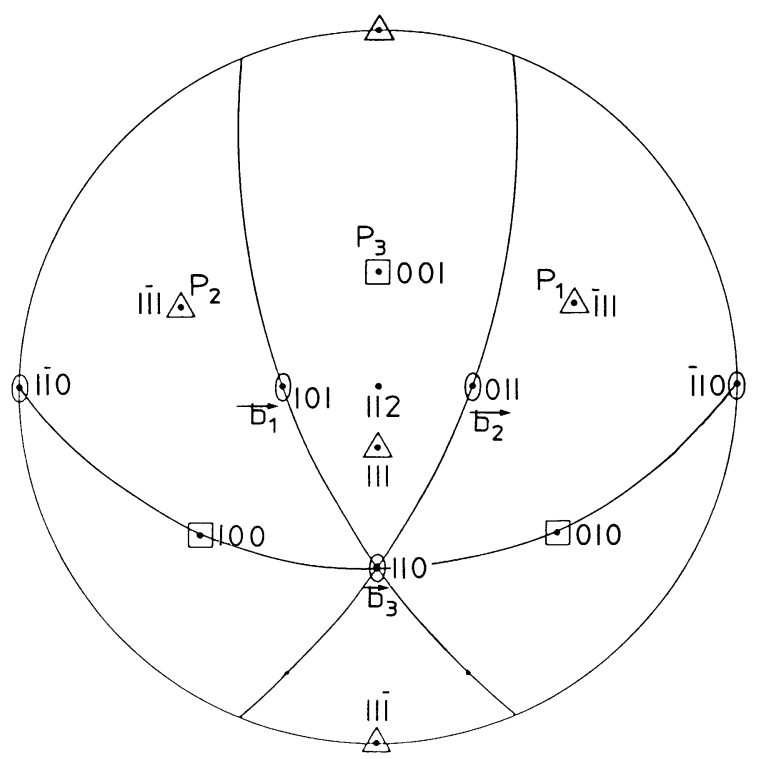

Fig. 7. - [112] stereographic projection. $\left(P_{1}, b_{1}\right)$ and $\left(P_{2}, b_{2}\right)$ are the primary octahedral systems. $\left(P_{3}, b_{3}\right)$ is the primary cube system. From [28]. 


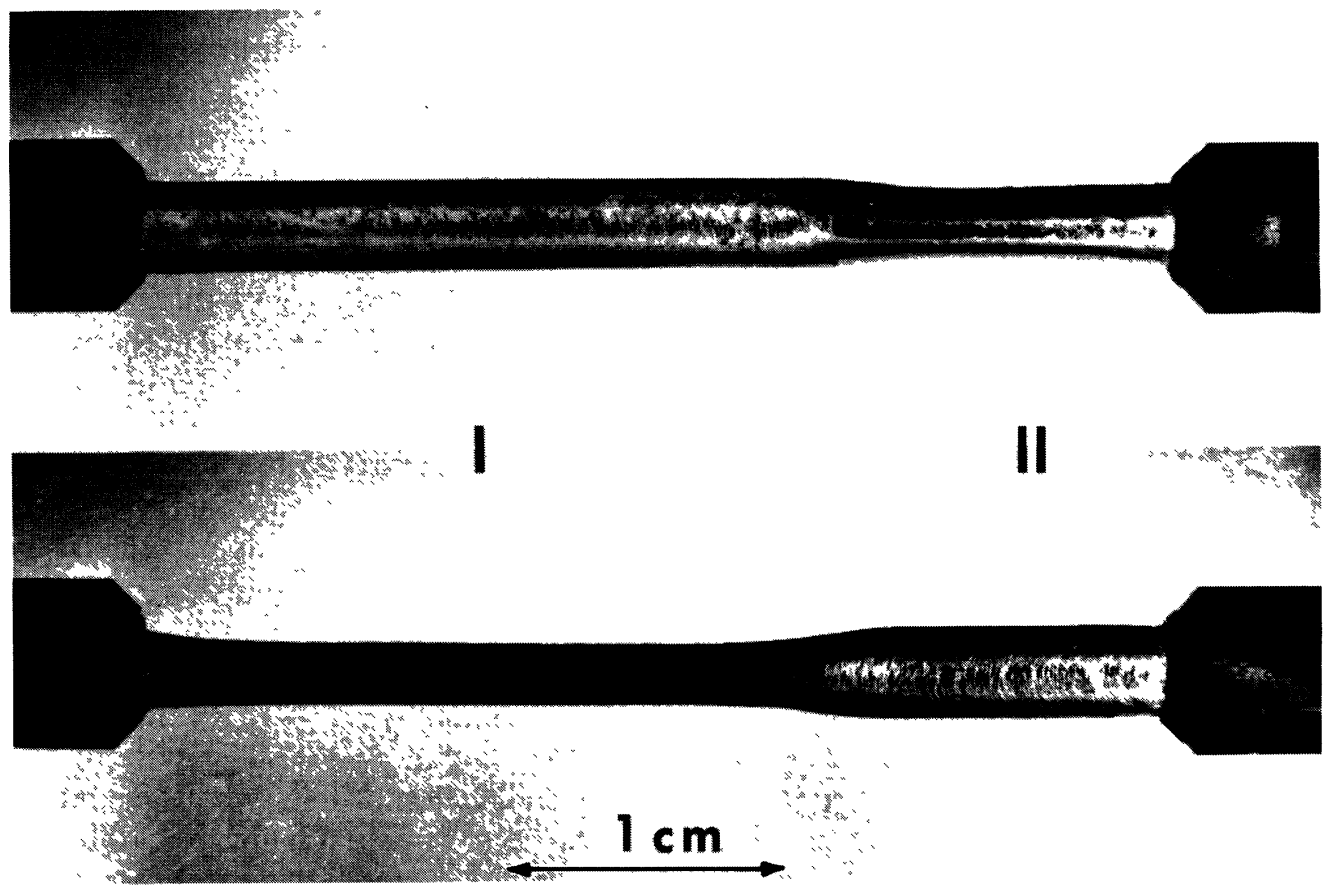

Fig. 8. - Two $90^{\circ}$ views of a [112] aluminium single crystal after deformation at $314^{\circ} \mathrm{C}$ with $\dot{\gamma}=12 \times 10^{-4} \mathrm{~s}^{-1}$. (001) and $\{111\}$ slip systems are activated in the two regions I and II, respectively [30].

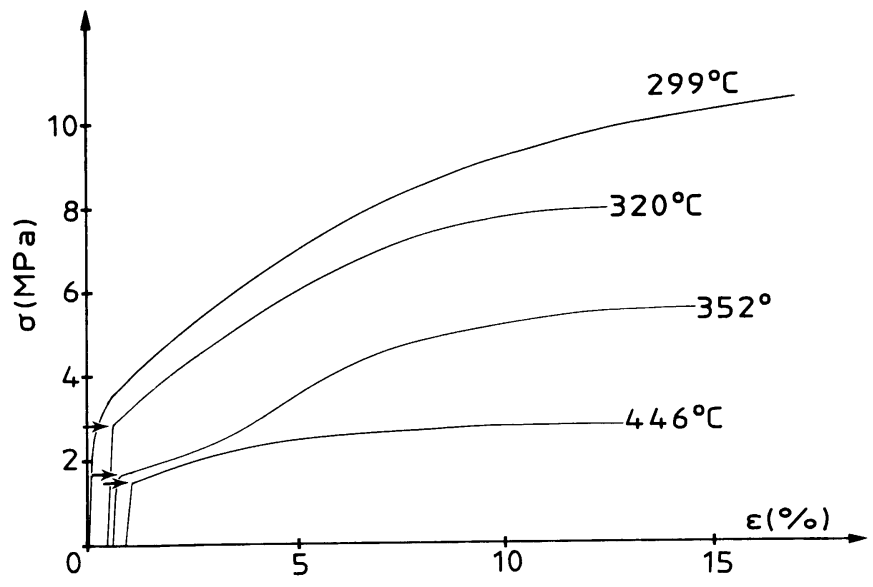

Fig. 9. - Stress-strain curves at different temperatures in [112] aluminium single crystals: $\dot{\gamma}=12 \times 10^{-4} \mathrm{~s}^{-1}$. When (001) glide is activated, the critical stress is indicated by an arrow [30].

non compact systems. It considers the motion on (001) of screw dislocations, which are normally dissociated on compact planes, as the rate controlling process. Under the applied stress, the dislocation recombines over a critical length to glide on (001). Under low stresses, the dislocation reaches the next dense row, forming a kink pair. The presence of long straight 


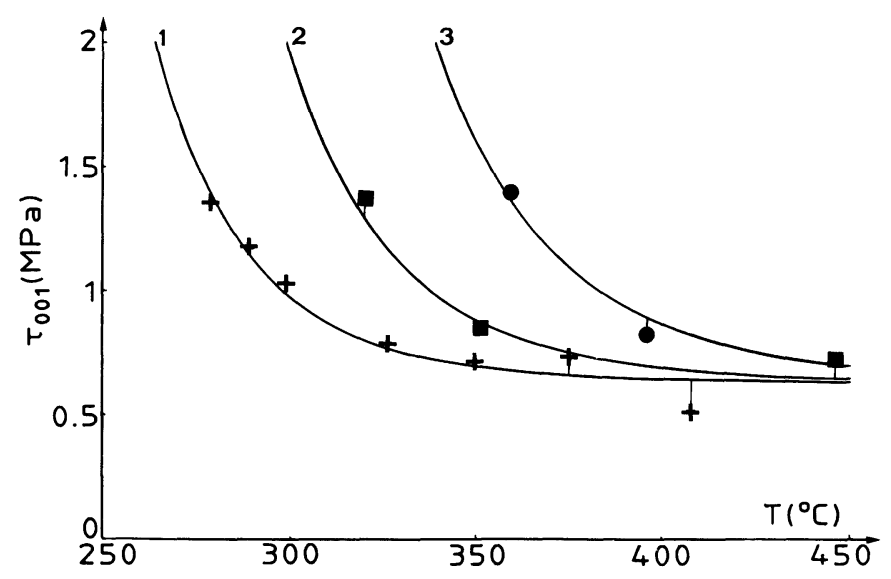

Fig. 10. - Variation in the CRSS $\tau_{001}$ for (001) glide with temperature for three strain rates in [112] aluminium single crystals : (+) $\dot{\gamma}=12 \times 10^{-5} \mathrm{~s}^{-1}$; (•) $\dot{\gamma}=12 \times 10^{-4} \mathrm{~s}^{-1} ;(\bullet) \dot{\gamma}=12 \times 10^{-3} \mathrm{~s}^{-1}$. The curves correspond to the kink-pair model [30].

screws which was evidenced above, indicates that the kink pair propagation is easier than its nucleation.

Analysis of the curves of figure 10 in terms of the rate equation of $\S 3.4$ below yielded a value of the activation energy at zero stress of $\Delta G_{001}^{\circ}=1.40 \mathrm{eV}$.

It can also be seen in figure 10 that the agreement betwen the rate equations and the experimental data is satisfactory, at least in the $150{ }^{\circ} \mathrm{C}$ temperature interval over which (001) glide could be observed.

Finally, the rate equations have been used to estimate the athermal temperature for $\{110\}$ slip in various FCC metals [30]. This agrees reasonably well with experimental values [33].

3.4 Common feAtures of the Generalized PeIERls MECHANism. - These can be summarized as follows :

- mechanical properties are closely related to individual dislocation mobilities and core geometries (see Fig. 11);

- the corresponding screw dislocations are straight as they move smoothly and continuously ;

- there are intensive multiplication processes, through the formation and development of closed loops (see Ref. [27] for magnesium);

- the velocity of screw dislocations, as derived by Escaig [11] under low effective stresses, is given by : $v=\alpha \nu\left(\frac{b}{\ell_{c}}\right)^{2} L \exp -\frac{\Delta G_{\mathrm{p}}}{k T}$, where the critical distance between two kinks is $\ell_{c}=\left(\frac{R}{\mu b^{2}}\right)^{1 / 2} \mu b / 2 \pi \tau^{*} ; \nu$ is the Debye frequency, $\Delta G_{\mathrm{p}}$ is the activation energy for Peierls glide, $R$ the recombination energy per unit length of dislocation, $\tau^{*}$ the effective stress and $\mu$ is the shear modulus. The velocity of dislocations is proportional to their length $L$, which has been directly verified in the case of magnesium [27] ;

- the activation energy can be expressed as : $\Delta G_{\mathrm{p}}=\Delta G_{\mathrm{p}}^{\circ}-\tau^{*} V$, where $\Delta G_{\mathrm{p}}^{\circ}$ equals twice the kink energy, i.e. $\Delta G_{\mathrm{p}}^{\circ} \sim 2 L^{\prime}\left(\mu b^{2} R\right)^{1 / 2}+2 U(U=$ constriction energy, $L=$ distance between two dense rows); 

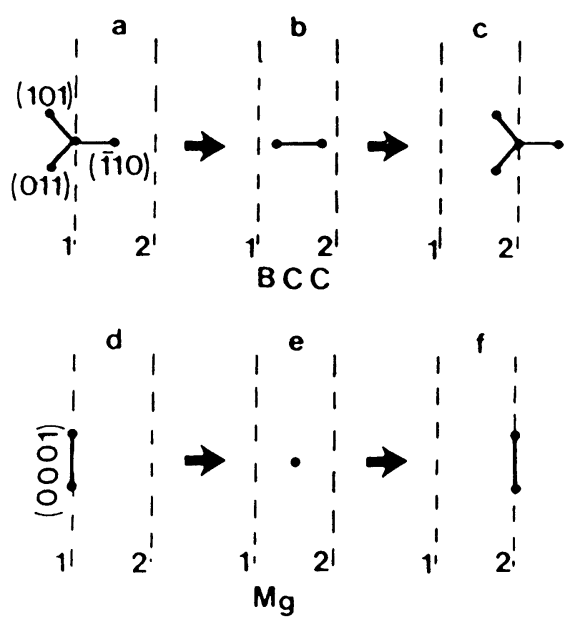

Fig. 11. - Comparison between the Friedel-Escaig mechanism in BCC and HCP metals. The screw dislocation is seen end-on.

- the activation area $A$ is of the order of $b . \ell_{c}$ and is small. This implies a strong increase of the elastic limit at low temperatures, which explains why non compact slip cannot be observed in FCC metals at low temperature ;

- because of the complex core splitting and the Escaig effect, Schmid law is often violated, as in the case of simple cross slip of $\S 2$. Some aspects of this problem have been discussed for non compact slip in aluminium [30].

\section{The locking-unlocking mechanism.}

This new mechanism has been experimentally detected on the basis of in situ experiments on prismatic slip of beryllium for the first time [34,35]. It appears to be operative in many different structures.

As in the case of the generalized Peierls mechanism, a screw core splitting occurs out of the glide plane. However, a metastable glissile core configuration exists, which allows free glide over several interatomic distances before the dislocation is locked again. The fundamental idea at the origin of the Peierls mechanism, i.e. the necessity of a periodic variation of the dislocation energy according to the lattice periodicity, is then lost.

4.1 Beryllium. - The mechanism was first suggested by Régnier and Dupouy (1970) [36] and then experimentally studied and fully described, in the case of the prismatic glide of beryllium $[34,35]$. The screws exhibit a jerky movement (Fig. 12), at variance with the Peierls mechanism. It is sketched in figure 12 . It can be shown that the glissile configuration in the prismatic plane is metastable and of higher energy than the sessile configuration spread in the basal plane. It thus appears that dislocations have a « fundamental state » which is the only one observed under static conditions and « excited states » of short lifetime, which can be observed under dynamic conditions only.

Unlocking and locking correspond to two elementary cross slip processes. The first is cross slip to a plane of higher energy. The description of Friedel [1, 3, 7] leads to lower activation energies than the former description of Schoeck and Seeger [4], and seems more realistic. The second is cross slip in a plane of lower energy similar to that discussed in $\S 2$. A statistical 

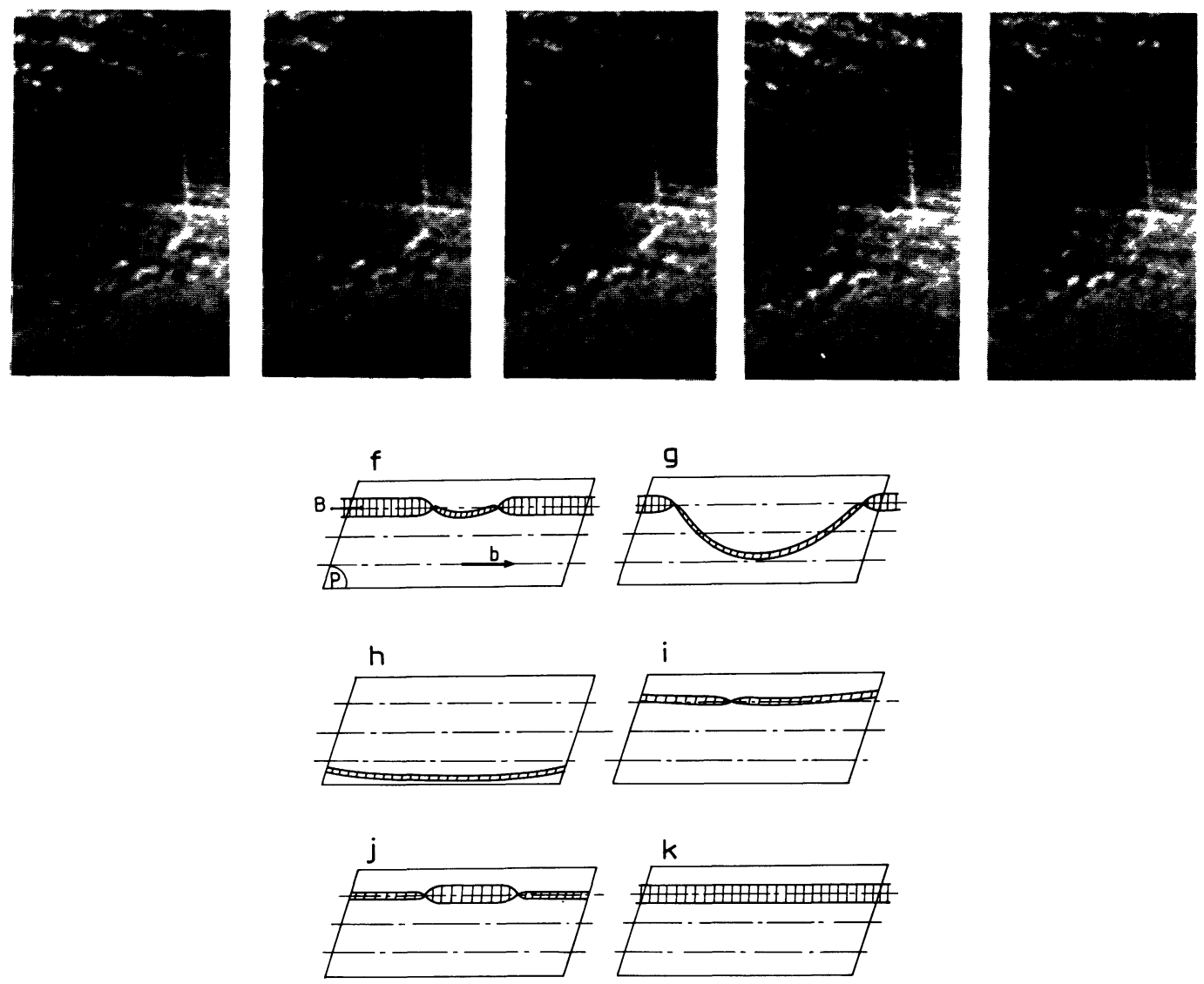

Fig. 12. - Locking-unlocking on screw dislocations in prismatic glide of beryllium at $300 \mathrm{~K}$. a) to e) : in situ sequence illustrating the jerky movement of the screws. Schematic representation of the unlocking process f) to h) and of the locking process i) to k). From [34, 35].

study of the waiting times of locked dislocations has been made, which leads to a single value for the probability of unlocking per unit time, at a given stress and temperature (Fig. 13). In the same way, the statistics of the jump lengths leads to a constant probability of locking per unit time. These probabilities are observed to vary according to the stress and the temperature, in agreement with the cross slip models.

When the temperature increases, the probability of locking increases and the length of the jump thus decreases, until it becomes equal to one interatomic distance (Peierls mechanism). Reciprocally, a Peierls mechanism can be replaced by the locking-unlocking mechanism at lower temperatures, provided a metastable glissile configuration exists. This has been demonstrated recently in the case of magnesium below $200 \mathrm{~K}$ [37]. The Peierls mechanism thus appears, surprisingly as a « high temperature » mechanism, with respect to lockingunlocking.

Locking-unlocking being really a cross slip mechanism, this continuity again emphasizes the importance of the cross slip description of the Peierls mechanism.

4.2 $\mathrm{Ni}_{3} \mathrm{Al}$. - In $\mathrm{Ni}_{3} \mathrm{Al}$ and nickel based superalloys, straight screw dislocations are also observed to move in $\{111\}$ and $\{100\}$ planes in a jerky manner [38, 39] (Fig. 14). 


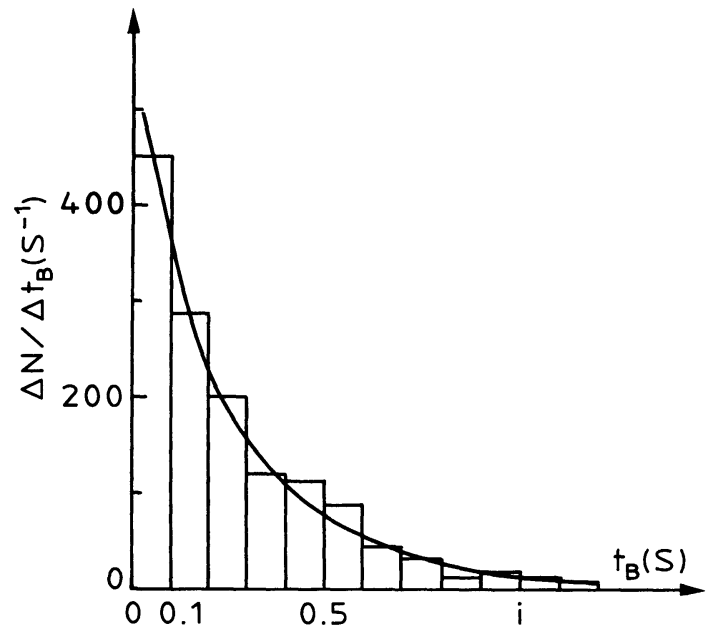

(a)

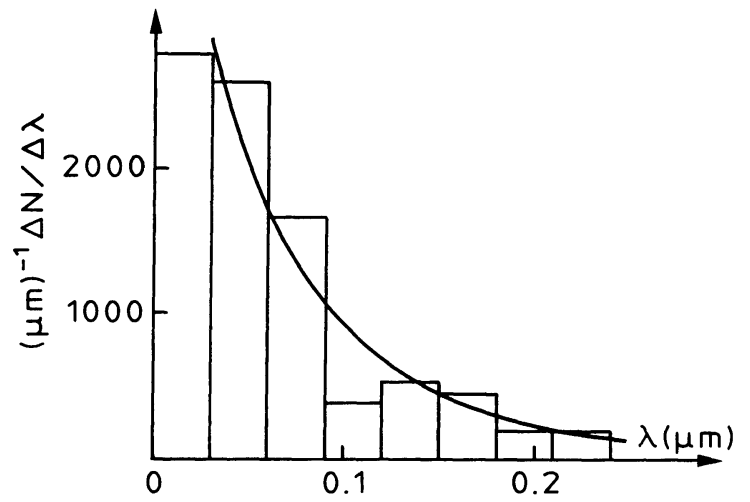

(c)

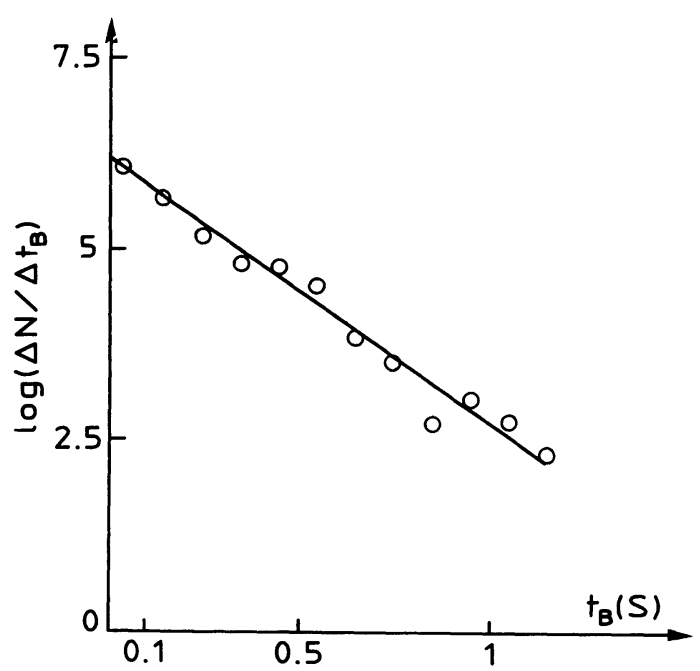

(b)

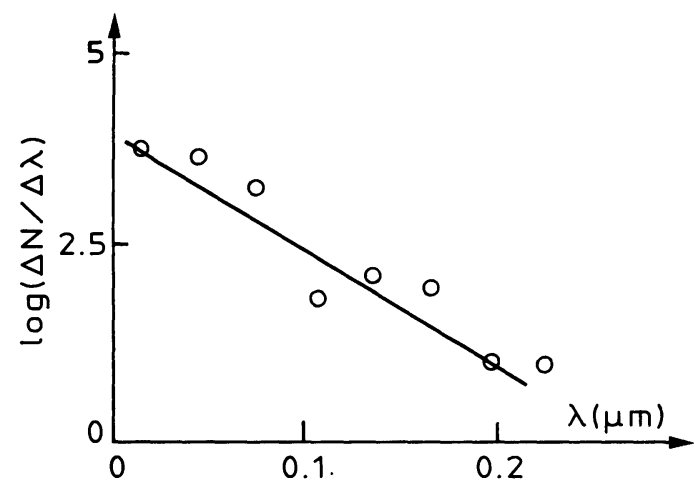

(d)

Fig. 13. - Data about screw dislocations in the locking-unlocking glide process in Be.

a) and b), waiting time measurements in the locked configuration. $\Delta N$ is the number of screw dislocations waiting during time $t_{\mathrm{B}}$ to $t_{\mathrm{B}}+\Delta t_{\mathrm{B}}$. (a) linear scale illustrating an exponential decrease; and (b) semilogarithmic scale. Slope $=P_{\mathrm{UL}}=3.5 \mathrm{~s}^{-1}$.

c) and d), jump length measurements (proportional to the flight time) in the unlocked configuration. $\Delta N$ is the number of screw dislocations jumping over a distance $\lambda$ to $\lambda+\Delta \lambda$. (c) linear scale illustrating an exponential decrease; and (d) semilogarithmic scale, the reciprocal of the slope is $\lambda=0.068 \mu \mathrm{m}$. From [35].
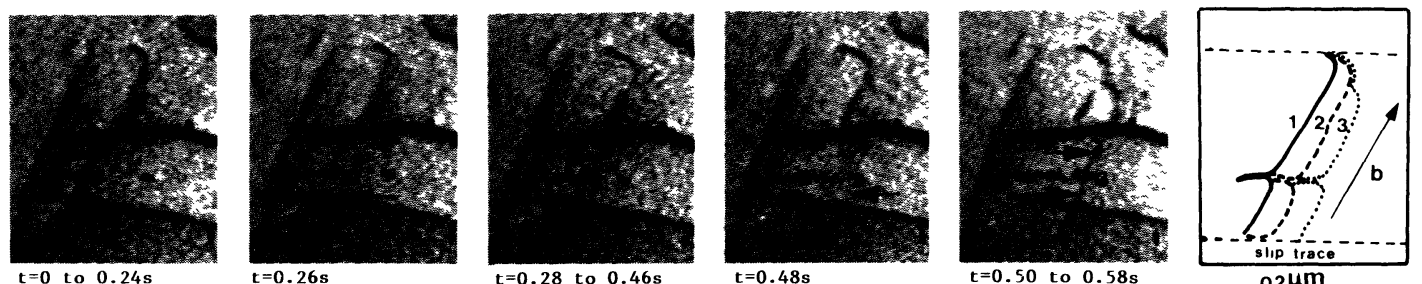

Fig. 14. - Locking-unlocking on screw dislocations gliding in cubic planes of the $\gamma^{\prime}$ phase of a nickelbased superalloy TEM in situ observation at $20^{\circ} \mathrm{C}$ [38]. 
In the case of glide in $\{100\}$ planes, core structure computations [40] lead to a configuration of minimum energy with the APB in $\{100\}$ and each superpartial spread in one of the two possible intersecting $\{111\}$ planes (Fig. 15). Weak beam and high resolution observations of dislocation cores [41] confirm this splitting geometry. To interpret the observed jerky movements, by analogy with the case of beryllium, it is thus necessary to assume that a second configuration of higher energy, glissile and spread in the $\{100\}$ plane, exists during very short times (Fig. 15). The movement is thus interpreted as a series of cross slip events between these two configurations, as in HCP metals. This hypothesis is confirmed by the waiting times and jump lengths measurements, which obey the same law as in beryllium [38].

In the case of glide in $\{111\}$ planes, the locking-unlocking movement is interpreted in a similar way, with a stable sessile configuration spread into the $\{111\}$ cross slip plane and a metastable glissile configuration spread in the $\{111\}$ glide plane [39].

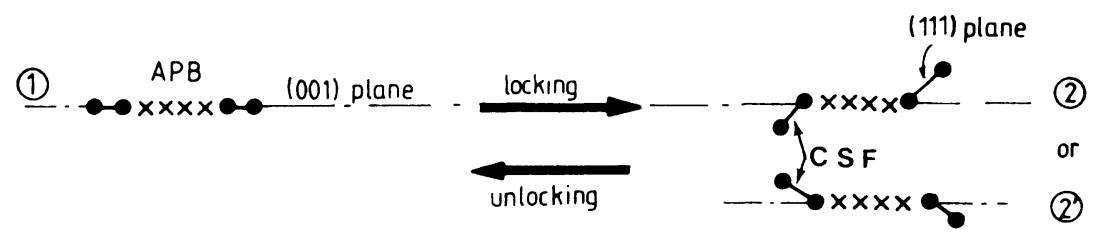

Fig. 15. - Schematic configuration of the core dissociation of a screw in $\{100\}$ planes of the $L_{12}$ structure. 1 = metastable configuration (planar = glissile). 2 and $2^{\prime}=$ stable configuration (non planar $=$ sessile).

4.3 COMMON FEATURES OF THE LOCKING-UNLOCKING MECHANISM. - The common features of the generalized Peierls mechanism also apply to locking-unlocking, except for the following points :

- the movement of dislocations is no longer smooth and continuous, but jerky ;

— their velocity is $v=v_{0} \frac{P_{\mathrm{UL}}}{P_{\mathrm{L}}}$, where $v_{0}$ is the instantaneous velocity in the glissile configuration and $P_{\mathrm{UL}}$ and $P_{\mathrm{L}}$ are the probabilities of unlocking and locking, respectively. $P_{\mathrm{UL}}$ and $P_{\mathrm{L}}$ can be expressed as :

$$
\begin{aligned}
P_{\mathrm{UL}} & =P_{\mathrm{ULO}} L \exp -\frac{\Delta G_{\mathrm{UL}}}{k T} \\
P_{\mathrm{L}} & =P_{\mathrm{LO}} L \exp -\frac{\Delta G_{\mathrm{L}}}{k T} \quad(L \text { dislocation length })
\end{aligned}
$$

and thus : $v=v_{0} \frac{P_{\mathrm{ULO}}}{P_{\mathrm{LO}}} \exp -\left(\frac{\Delta G_{\mathrm{UL}}-\Delta G_{\mathrm{L}}}{k T}\right)$

independent of the dislocation length $L$.

- The activation energy is the difference between the activation energies of the two cross slip processes. The following expression has been given by Friedel (1959) [3] ;

$$
\Delta G_{\mathrm{UL}}=U_{\mathrm{CS}}+\frac{2^{5 / 2} R^{3 / 2}\left(\mu b^{2}\right)^{1 / 2}}{3 \tau^{*} b}
$$


$U_{\mathrm{CS}}$ constriction energy of the sessile configuration, and $\Delta G_{\mathrm{L}} \sim$ constriction energy of the glissile configuration ;

- the corresponding activation area is generally higher than for the Peierls mechanism (except for very high stresses) which leads to a smaller elastic limit increase at decreasing temperatures.

\section{The origin of strength anomalies.}

Several materials, including beryllium in prismatic glide and $L_{12}$ ordered alloys, exhibit an anomalous flow stress increase at increasing temperature. The most current models for this behaviour are based on the thermally activated and irreversible locking of dislocations by cross slip [36, 42]. This corresponds to the first step only of the locking, unlocking mechanism.

A study of the glide of dislocations in prismatic planes of beryllium reveals a behaviour which is at variance with this prediction, since locking-unlocking is observed over the whole temperature range, including the domain of the anomalous flow stress increase $[34,35]$. The origin of the strength anomaly is thus an increase in the difficulty of cross slipping as the temperature rises due to an increase of the recombination energy $R$. In the elastic approximation, this would correspond to a decrease of the stacking fault energy as the temperature is increased. Similar behaviour has also been observed in a nickel based alloy [38], in the case of glide in $\{100\}$ planes, and the same mechanism could also be at the origin of the strength anomaly of $\mathrm{Ni}_{3} \mathrm{Al}$, in the case of $\{111\}$ glide [39]. It can also account for the thermally activated dislocation motion evidenced at the strength anomaly [43]. It is clear that since all cross slip mechanisms are very sensitive to the recombination energy $R$, i.e. the stacking fault energy, the possible temperature variation of these parameters should be included in the models.

\section{Creep at intermediate and high temperature.}

The variation of the creep activation energies with temperature, as reviewed by Poirier in pure FCC and HCP metals [44], suggests that different mechanisms are rate controlling in different temperature domains (see Fig. 16). In the case of aluminium and FCC metals, the

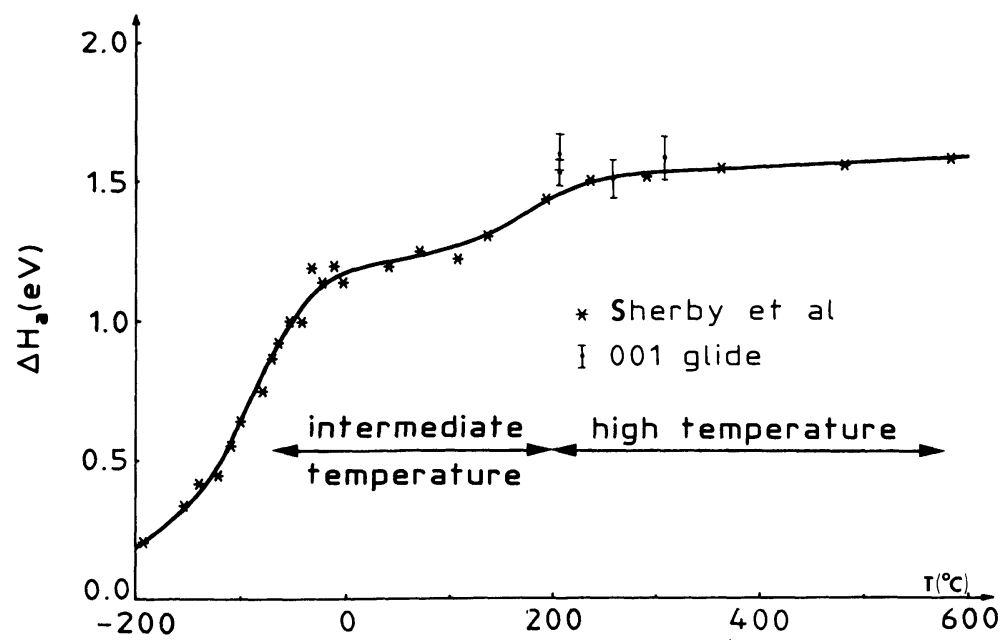

Fig. 16. - Creep activation enthalpies measured by Sherby et al. (1957) in aluminium polycrystals [50]. The results obtained in [112] single crystals between 200 and $320^{\circ} \mathrm{C}$ are also reported for 001 glide [30]. 
plateau of activation energy at intermediate temperature has been attributed to cross slip (Friedel [3], Lytton et al. [6]), while the high temperature range has been considered to be climb controlled through self diffusion. Conversely, for HCP metals, the intermediate temperature regime was attributed to self diffusion, while the higher activation energy in the high temperature domain was thought to correspond to dislocation cross slip from the basal to the prism plane [44].

More recent detailed models have been proposed for cross-slip-controlled creep mechanisms. Friedel (1977) [45] suggests that creep is controlled by the dissociation of dislocations along the plane of the network, their escape necessarily involving cross-slip to the more highly stressed glide plane. Poirier [46] considers that the creep rate is controlled by a recovery mechanism inside the subgrains : this can occur either by the annihilation through cross slip of the screw portions of the loops at intermediate temperature, or through climb of the edge portions at higher temperatures.

These suggestions can now be pursued in more detail thanks to newly available transition electron microscope observations.

6.1 AluminiUm (AND THE Al-Zn SOlID SOlUTION) AT INTERMEDIATE TEMPERATURES. Strain is associated with the glide of dislocations escaping from subboundaries [47], which necessitates high local internal stresses. They have been measured directly [48] and they originate in the subboundary migration process [49].

The creep rate is thus controlled by the glide of some of the subboundary segments on $\{001\}$ planes and the activation energy corresponds to the energy of one kink in $\{001\}$ (see Fig. 17) with a value at zero stress $\Delta G_{0} \sim 0.7 \mathrm{eV}$. This is in reasonable agreement with the enthalpies of figure 16, after the entropy correction has been made [50].
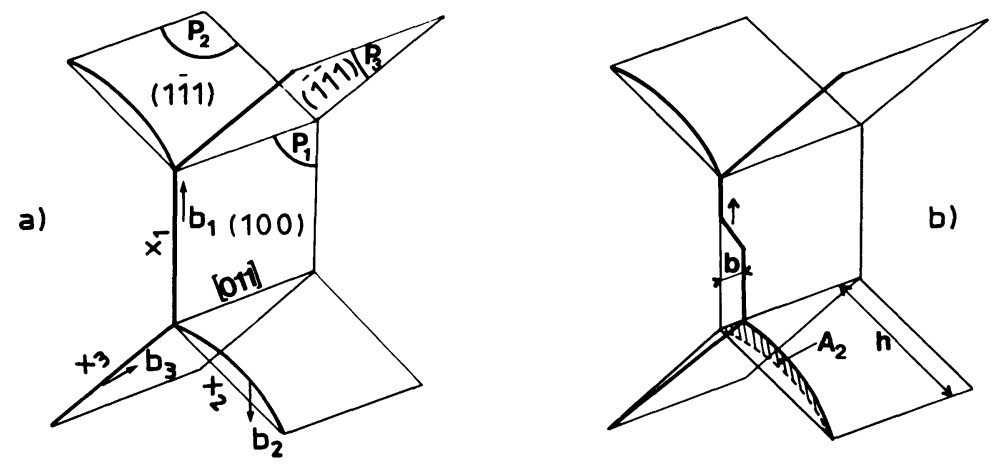

Fig. 17. - Schematic representation of the subboundary migration process. a) $x_{i}(i=1,2,3)$ are the 3 dislocation families of the subboundary mesh. $b_{i}$ are their respective burgers vectors, $P_{i}$ there respective glide planes. b) Onset of migration while the screw segment $x_{1}$ glides on (100). From [49].

6.2 Aluminium AT High TEMPERATÚRE. - The creep rate is controlled by non compact slip of screw dislocations across the subgrains at least at the onset of the high temperature domain. This is supported experimentally by the observation of long rectilinear screw dislocations, which were pinned under load at the end of the creep test in an $\mathrm{Al}-\mathrm{Zn}$ solid solution (see Fig. 18) [48]. Creep activation energy values were measured in [112] aluminium single crystals above $200{ }^{\circ} \mathrm{C}$ while the slip traces indicated extensive glide on (001) [28]. The energy values are in figure 16 and are in close agreement with previous measurements in polycrystals [50]. In this case $\Delta G_{0}$ is twice the (001) kink energy, i.e. of the order of $1.34 \mathrm{eV}$ [30]. 


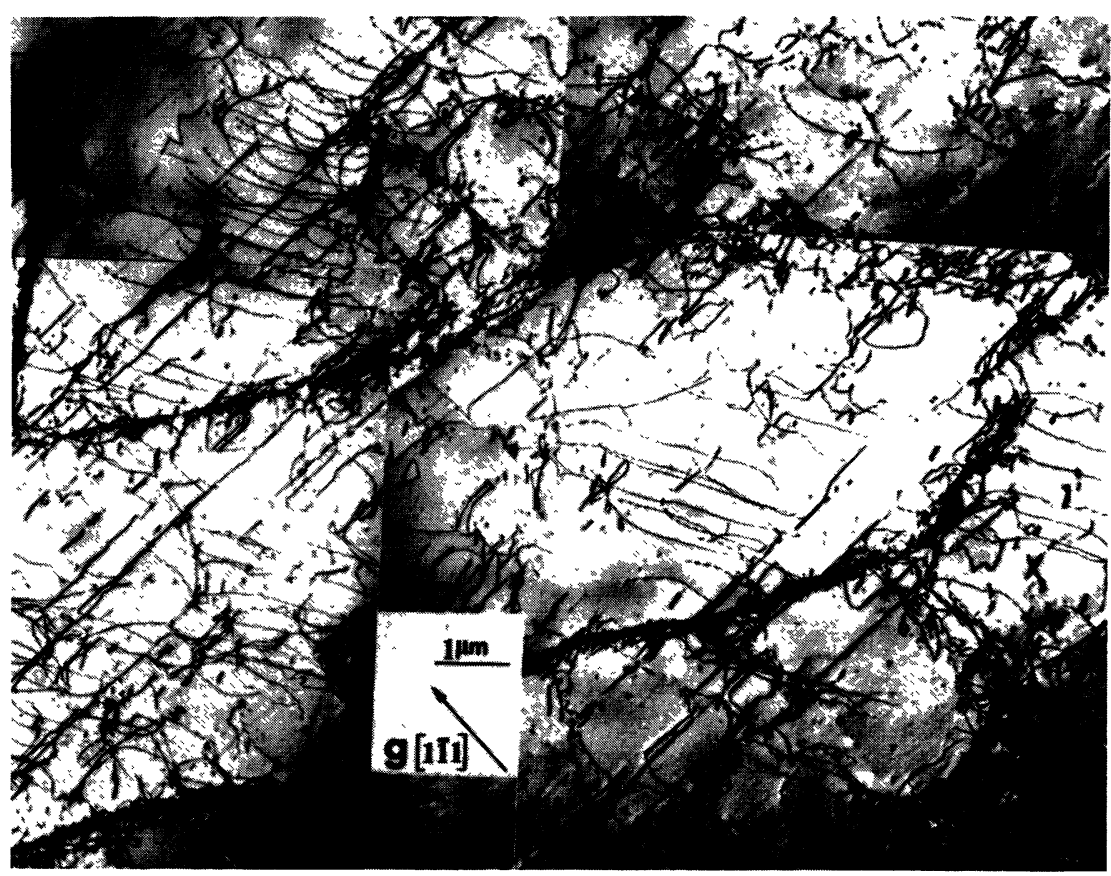

Fig. 18. - Straight screw dislocation substructure after creep. Al-11 wt. \% $\mathrm{Zn}$ polycrystal. $T=$ $250{ }^{\circ} \mathrm{C}, \sigma=17 \mathrm{MPa}, \varepsilon=22 \%$. Dislocations are pinned under load [48].

6.3 MAgNESIUM AT INTERMEDIATE TEMPERATURE. - The results of the in situ experiments described in $\$ 3$ lead to activation energy values for prismatic glide, that are not compatible with those measured in creep at high temperatures. The creep mechanism at high temperatures is therefore not yet fully understood. However, at intermediate temperatures, figure 19 shows that the activation energy values for prismatic glide as a function of temperature are compatible with those measured in creep [27]. Prismatic slip can therefore be an alternate mechanism for creep at intermediate temperatures.

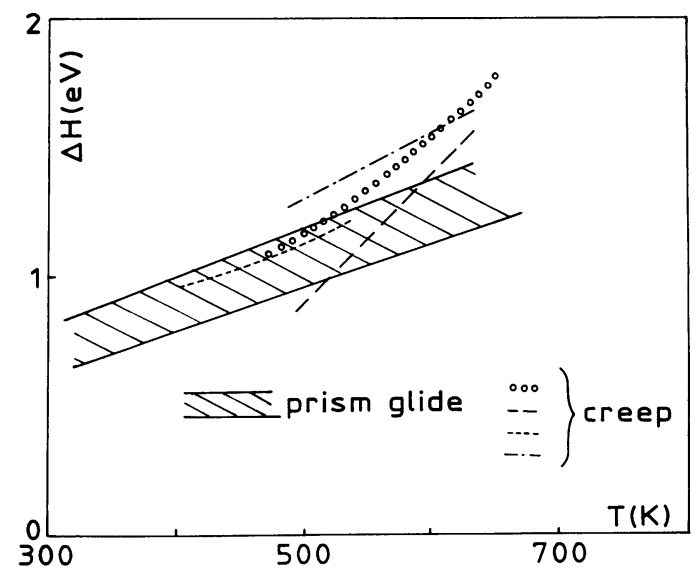

Fig. 19. - Comparison of activation enthalpies in magnesium, for creep of polycrystals and for prismatic glide. Creep data from 4 different studies, quoted by [27]. 


\section{Deformation stages.}

In face centred cubic metal single crystals, three deformation stages on the stress strain curves have been evidenced at temperatures below or equal to room temperature (Friedel, 1956 [1] and 1959 [3]). As already discussed in $\S 2$, recent experimental information about cross slip in copper shows that the critical stress for this mechanism is clearly different from $\tau_{\text {III }}$, as well as its variation with the temperature [14]. Cross slip is probably active during stage III, but mixed together with other mechanisms such as the destruction of some types of junction reactions [51].

However, at large strains and room temperature, a stage IV is observed, which is characterized by a new linear hardening [52]. At higher temperatures, stage IV has also been observed in covalent materials [53]. The same authors have detected a similar behavior in face centered cubic metals, by analysing previously published stress strain curves on $\mathrm{Al}$ [54] and on $\mathrm{Au}$ [55]. In a recent study of [112] copper single crystals above $200^{\circ} \mathrm{C}$, it has been shown that stage IV is also present, and followed by additional stages [56]. A careful examination of the slip traces has shown that the onset of stage IV corresponds to the activation of non compact slip which itself involves cross slip (§ 3.3).

\section{Conclusions.}

In this review, we have attempted to show how realistic ideas about basic cross slip mechanisms, which were formulated about thirty years ago, are still enlightening. This is quite remarkable nowadays, as the general tendency is to ignore the literature which is more than ten years old.

These ideas stimulated the complete derivation of the cross slip mechanism when the dislocation is dissociated in the glide plane or out of it. Later, experimental data were produced, mostly based on in situ observations in the electron microscope and accurate mechanical tests. They have confirmed the cross slip model both in copper and in magnesium oriented for prismatic glide. In these two cases, realistic values of activation energies and volume values have been obtained. The kink pair mechanism for prismatic glide could also be extended with success to non compact slip in aluminium. Intermediate and high temperature domains have been determined for which the cross slip mechanisms seem to impose well established creep activation energy values. A new mechanism of locking-unlocking of the screws has been evidenced experimentally. The latter seems to be rather common, the kink pair mechanism being a special case. It accounts for yield stress anomalies in a variety of situations such as prismatic slip in beryllium, titanium, etc... and in the $\mathrm{Ni}_{3} \mathrm{Al}$ compound oriented for 111 or 001 slip.

The amount of work needed to complete the above results is quite large. In the FCC structure, cross slip should be experimentally studied in crystals with various stacking fault energies ; the same remark holds for non compact slip on various planes. This will allow a better check of the models. In prismatic glide of HCP crystals and in the $L_{12}$ structures, accurate mechanical tests should be performed to detect macroscopic evidence of the lockingunlocking versus kink pair mechanism. The connection between the former mechanism and yield stress anomalies should be better established in crystals other than beryllium.

\section{Acknowledgements.}

The authors acknowledge stimulating discussions with Dr. P. W. Hawks about this paper. They thank Fonds National Suisse de la Recherche Scientifique for the financial support of part of this work. 


\section{References}

[1] Friedel J., in « Les Dislocations » (Gauthier-Villars, Paris) 1956.

[2] Stroh A. N., Proc. R. Soc. A 223 (1954) 404.

[3] FRIEDEL J., in «Internal stresses and fatigue of metals » (Elsevier, Amsterdam) 1959, p. 220.

[4] Schoeck G., Seeger A., in « Defects in Crystalline Solids » (Phys. Soc., London) 1955, p. 340.

[5] WOLF H., Z. Naturforsch. 15a (1960) 180.

[6] Lytton J. L., Shepard L. A., Dorn J. E., Trans. Metall. Soc. AIME 212 (1958) 220.

[7] FRIEDEL J., "Dislocations » (Pergamon) 1964.

[8] HAASEN P., in «Lattice defects and their interactions » (Hasiguti, New York) 1967, p. 437.

[9] FRIEDEL J., « Dislocation in solids », F. N. Nabarro Ed. (North Holland, New York), vol. 1, 1979, p. 26.

[10] EscaIG B., Thèse, Université d'Orsay, no A382 (1968).

[11] Escaig B., J. Phys. France 29 (1968) 255.

[12] Friedel J., in " Dislocations and mechanical properties of crystals » (Wiley, New York) 1957, p. 330.

[13] Bonneville J., Escaig B., Acta Met. 27 (1979) 1477.

[14] Bonneville J., Escaig B., Martin J. L., Acta Metall. 36 (1988) 1989.

[15] Paidar V., Pope D. P., Vitek V., Acta Metall. 32 (1984) 435.

[16] Hirsch P. B., 5th Int. Cong. on Crystallography (Cambridge) 1960, p. 139.

[17] Yoshinaga H. and HoRIUCHI R., Trans. Japan Inst. Metals 5 (1963) 14.

[18] Kroupa F., Phys. Stat. Sol. 3K (1963) 391.

[19] Schottky G., Seeger A., Speidel V., Phys. Stat. Sol. 9 (1965) 231.

[20] Vitek V., Phys. Stat. Sol. 18 (1966) 687.

[21] Escaig B., Phys. Stat. Sol. 28 (1968) 463.

[22] Seeger A., Dislocations 1984, P. Veyssière, L. Kubin and J. Castaing Eds. (CNRS, Paris), 1984, p. 141.

[23] Friedel J., Comm. Solid State Phys. 1 (1968) 24.

[24] Furubayashi E., J. Phys. Soc. Japan 27 (1969) 130.

[25] Louchet F., Kubin L. P., Vesely D., Philos. Mag. A 39 (1979) 433.

[26] Naka S., Lasalmonie A., Costa P., Kubin L. P., Philos. Mag. A 57 (1988) 717.

[27] Couret A., Caillard D., Acta Met. 33 (1985) 1447 and 1455.

[28] Carrard M., Martin J. L., Philos. Mag. A 56 (1987) 391.

[29] Le Hazif R., Dorizzi P., Poirier J. P., Acta Met. 21 (1973) 903.

[30] Carrard M., Martin J. L., Philos. Mag. A 58 (1988) 491.

[31] Anongba P., Bonneville J. and Verger-Gaugry J. L., Scripta Met. 21 (1987) 777.

[32] Couret A., Caillard D., Acta Metall. 36 (1988) 2515.

[33] Le Hazif R., Poirier J. P., Acta Metall. 23 (1975) 863.

[34] Couret A., Caillard D., in Strength of Metals and Alloys (Proceedings ICSMA8, Pergamon, New York) 1988, p. 211.

[35] Couret A., Caillard D., Philos. Mag. A 59 (1989) 783 and 801.

[36] Régnier P., Dupouy J. M., Phys. Stat. Sol. 39 (1970) 179.

[37] COURET A., Thèse No. 490 (1989).

[38] Clément N., Caillard D., Lours P., Coujou A., in Strength of Metals and Alloys (Proc. ICSMA8) Ibidem, p. 205.

[39] Caillard D., Clément N., Couret A., Lours P., Coujou A., Philos. Mag. Lett. 58 (1988) 263.

[40] Yamagushi M., Païdar V., Pope D. P., Vitek V., Philos. Mag. A 45 (1982) 867.

[41] Baluc N., Karnthaler H. P., Mills M. J., Proc. EUREM 88, Int. Phys. Conf. Ser. 93, 2 (1988) 463.

[42] Kear B. H., Wilsdorf H. G. F., Trans. AIME 224 (1962) 382.

[43] Baluc N., Stoiber J., Bonneville J., Martin J. L., Israël J. Technol. 24 (1988) 269.

[44] PoIRIER J. P., « Plasticité à haute température des solides cristallins » (Eyrolles, Paris) 1976, p. 52.

[45] Friedel J., Rev. Phys. Appl. 12 (1977) 1649. 
[46] Poirier J. P., Rev. Phys. Appl. 11 (1976) 731.

[47] Caillard D., Martin J. L., Acta Metall. 31 (1983) 813.

[48] Morris M. A., Martin J. L., Acta Metall. 32 (1984) 549.

[49] Caillard D., Philos. Mag. A 51 (1985) 157.

[50] Sherby O. D., Lytton J. L., Dorn J. E., Acta Metall. 5 (1957) 219.

[51] SaAda G., Acta Metall. 8 (1960) 841.

[52] Gil Sevillano J., Van Houlte P., Aernoudt E., Progr. Mat. Sci. 25 (1980) 69.

[53] SCHRÖter W., SieThOFF H., Z. Metallkunde 75 (1984) 482.

[54] Nicklas B., Mecking H., Proceedings ICSMA5 (Pergamon, Oxford) 1979, p. 351.

[55] Mecking H., Work hardening in tension and fatigue (Met. Soc. AIME, New York) 1977, p. 67.

[56] Anongba P., Bonneville J., Martin J. L., Strength of Metals and Alloys (Proceedings ICSMA8) Ibidem, p. 265. 